Pp. 1-7

DOI: $10.1089 / \mathrm{gtmb} .2017 .0177$

\title{
The Prognostic Value of Combinations of Genetic Polymorphisms in the ITGB3, ITGA2, and CYP2C19*2 Genes in Predicting Cardiovascular Outcomes After Coronary Bypass Grafting
}

\author{
Yuriy I. Grinshtein,, Aleksandra A. Kosinova, Igor Y. Grinshtein?, \\ Tatyana N. Subbotina, and Andrey A. Savchenko ${ }^{4}$
}

\begin{abstract}
Aim: To determine if there is an association between the single nucleotide polymorphisms (SNPs): rs2046934, rs1126643, rs5918, rs6065, rs4244285; rs4986893 and the occurrence of cardiovascular events (CVE) in patients following coronary artery bypass grafting (CABG) surgery.

Materials and Methods: The study included 130 CABG patients with stable angina grades II-IV. After CABG 69 of the patients were treated with acetylsalicylic acid (ASA) alone, and 61 received dual antiplatelet therapy (ASA+clopidogrel). Platelet function was assessed by light transmission aggregometry with adenosinediphosphate and arachidonic acid. The SNPs were identified by real-time polymerase chain reaction (PCR) with electrophoresis detection. The mean follow-up period was equal to $10.9 \pm 5.2$ months. The primary end point included the composite of all-cause mortality, myocardial infarction (MI), and ischemic stroke.

Results: During the follow-up period $12 \mathrm{CVE}$ were registered: 3 deaths, 6 MI, 3 strokes. Patients with composite mutant alleles of ITGB3+CYP2C19*2 or CYP2C19*2+ITGA2, and with the mutant allele $(* 2)$ of CYP2C19, met end points more often than patients with other gene combinations (wild-type homozygotes, presence of one mutant allele of ITGB3 or ITGA2, the composite of mutant alleles of ITGB3+ITGA2 or ITGB3+ITGA2+CYP2C19*2; hazard ratio $=4,95 \%$ confidence interval: $2.19-7.29, p=0.008$ ).

Conclusion: Carriage of a combination of mutant alleles in multiple genes including ITGB3+CYP2C19*2 or CYP2C19*2+ITGA2 or CYP2C19*2 are possible predictors of CVE in patients after CABG.
\end{abstract}

Keywords: artery bypass surgery, cardiovascular events, genetic predictors

\section{Introduction}

$\mathbf{P}$ LATElETS Play a critical role in atherothrombosis. The platelet phenotype has wide variability due to heritable differences in its reactivity, quantity, cell size, and membrane receptors' functions (Geisler et al., 2013). The studies of siblings, twins, and families with a history of coronary artery disease (CAD) have documented that intraindividual responsiveness is highly reproducible over time, regardless of the agonist tested or the method chosen for assessment of aggregation activity. These findings provide strong evidence of a high heritability level of platelet function that has prompted numerous attempts to define the genetic basis for platelet function variability (Jones et al., 2009). Up to $30 \%$ of platelet function variability could be explained by genetic heritability (Quinn and Topol, 2001).

Von Willebrand factor receptors, adenosine diphosphate (ADP) receptors, collagen and fibrinogen receptors are the main platelet receptors to take part in cell activation and thrombus formation (Zuern et al., 2010).

Genetic research has carefully considered the association of the above-mentioned receptors' gene polymorphisms with acute coronary syndrome, other cardiovascular diseases, and atherothrombogenic outcomes (Cavallari et al., 2007; Maguire et al., 2008; Hoppmann et al., 2014; Moon et al., 2017). However, there is less evidence concerning the association of

\footnotetext{
${ }^{1}$ Therapeutic Department of Institute of Postgraduate Education, Krasnoyarsk State Medical University is named after prof.V.F.VoynoYaseneckiy, Krasnoyarsk, Russian Federation.

${ }^{2}$ Department of Polyclinic Therapy, Family Medicine and Healthy Way of Life, Krasnoyarsk State Medical University is named after prof.V.F.Voyno-Yaseneckiy, Krasnoyarsk, Russian Federation.

${ }^{3}$ Scientific and Practical Laboratory of Molecular and Genetic Methods of Research, Siberian Federal University, Krasnoyarsk, Russian Federation.

${ }^{4}$ Research Institute of Medical Problems of the North, Siberian Division of the Russian Academy of Medical Sciences, Krasnoyarsk, Russian Federation.
} 
platelet receptors' single nucleotide polymorphisms (SNPs) with ischemic outcomes after coronary artery bypass grafting (CABG) (Muslimova et al., 2017; Sarikaya et al., 2017).

As we know, carrying of a genetic polymorphism could manifest phenotypically or remain inapparent. In case of atherothrombosis, various risk factors could trigger the appearance of a trait encoded by relevant polymorphism.

CABG could be one of the predisposing factors of vessel thrombosis. On the one hand it is a surgery aimed to improve the quality of life, on the other it is a huge stress for the body and hemostasis system. On-pump surgery damages cells, and active substances flow into the blood: platelet adhesion and aggregation stimulators, intercellular stimulators, endothelium and system inflammation mediators; younger and more active cells, particularly platelets, merge the bloodstream (Grinshtein et al., 2009). The background of all this processes is atherosclerosis with system inflammation. It is also known that the risk of antiplatelet drugs resistance (aspirin and clopidogrel-drugs for secondary prevention of thrombotic events) is enhanced after CABG (Grinshtein et al., 2016). Therefore, genetic polymorphisms of cytochrome P450, of the enzyme that convert the prodrug to the active metabolite in the liver, could be considered in association with cardiovascular outcomes (Moon et al., 2017).

Thus, the aim of our research was to study the association of SNPs: rs2046934 (H1/H2: 744T<C) on P2RY12 (encoding platelet ADP receptor); rs1126643 (807C $>$ T) on ITGA2 (encoding collagen receptor); rs5918 $(176 \mathrm{~T}>\mathrm{C})$ on ITGB3 (encoding fibrinogen receptor); rs6065 (Thr145Met) on GP1BA (encoding platelet receptor for Von Willebrand factor); rs4244285 (*2) (681G>A) and rs4986893 (*3) (636G $>\mathrm{A}$ ) on CYP2C19 (encoding cytochrome P450 activity) with cardiovascular events (CVE) in patients with CAD after CABG.

\section{Materials and Methods}

The study was conducted in the Krasnoyarsk Federal Center of Cardiovascular Surgery from September 2012 to December 2015. The study comprised 130 Caucasian patients (mean age of $62 \pm 8.3$ years old) with stable angina pectoris, grade II-III according to the Canadian Cardiovascular Society classification.

All patients underwent CABG, 113 patients (87\%) underwent on-pump CABG, and 17 patients $(13 \%)$ underwent off-pump CABG.

Inclusion criteria were as follows: stable angina pectoris grades II-IV, coronary artery atherosclerosis, proved by coronary angiography, and written informed consent.

Exclusion criteria were as follows: renal failure, hepatic failure, peptic ulcer and/or 12 duodenal ulcer in the acute stage, and acetylsalicylic acid (ASA) or clopidogrel intolerance.

The control group included 185 healthy Caucasian volunteers (74 women, 111 men) of mean age around 44.2 \pm 9.8 years, who were blood donors in Krasnoyarsk area blood center from January 2012 to December 2015.

The study protocol was approved by the Ethics Committee of the Krasnoyarsk State Medical University and conducted according to the Helsinki Declaration with application of Good Clinical Practice guidelines with written consents obtained from all participants. Throughout the hospitalization all patients were receiving therapy according to the Russian
Cardiology Society guidelines. Patients stopped the antiplatelet treatment at least 5 days before $\mathrm{CABG}$. In the postsurgical period, patients were prescribed $100 \mathrm{mg}$ of enteric form of ASA alone (69 patients), or $100 \mathrm{mg}$ ASA+clopidogrel $75 \mathrm{mg}$ per day (61 patients) since the first day after CABG.

Blood specimens from the patients for platelet aggregation assay were obtained using test tubes containing $3.8 \%$ sodium citrate filled at the ratio 9:1. Samples were processed within $2 \mathrm{~h}$ after blood collection. For genetic analysis, wholeblood samples were obtained from participants and collected in EDTA tubes, stored at $-18^{\circ} \mathrm{C}$. Platelet aggregation was measured using a light transmission aggregometer (ChronoLog 490) with aggregation inductors: ADP $5 \mu \mathrm{M}$ or arachidonic acid (AA) $1 \mathrm{mM}$ before CABG and on 1st-3rd, 8th-10th day after $\mathrm{CABG}$.

The genetic analysis was conducted in the Hematological Research Center of the Federal State-funded Institution of Russian Ministry of Health.

Genomic DNA from whole-blood samples was extracted by standard methods using the reagent "DNA-EXPRESSblood" (Litekh). Genetic polymorphisms were detected by polymerase chain reaction with the use of primers and reagents for amplification "SNP-express" and "SNP-expressRT" (Litekh) for electrophoretic detection of amplification products (by thermocycler Tercik; DNA-Technology) and detection of amplification products in real time (by thermocycler IQ-5; Bio-Rad) (Lytech.ru, 2011). In the obtained DNA samples, the following polymorphisms were identified:

- $\mathrm{H} 1 / \mathrm{H} 2$ haplotypes of the ADP platelet receptor gene P2Y12, determined by assessing i-744T >C (rs2046934; catalog No. for set: 01180);

- collagen receptor gene ITGA2 (807C>T, rs1126643; catalog No. for set: S01155);

- fibrinogen receptor gene ITGB3 (176 T>C, rs5918; catalog No. for set: S01106);

- and von Willebrand factor receptor gene GP1BA (Thr145Met, rs6065) (catalog No. for set: 01179).

We equally studied the SNPs of cytochrome P450 gene CYP2C19*2 (681G>A, rs4244285; catalog No. for set: S01323) and CYP2C19*3 (636G>A, rs4986893; catalog No. for set: S01324).

The mean follow-up period lasted 10.9 \pm 5.2 months. Compliance was estimated by telephone contact. Only patients with high compliance were enrolled in the study. The primary clinical end point was the cumulative incidence of acute myocardial infarction (AMI), cerebral stroke, and all causes death.

\section{Statistical analysis}

Data are presented as the mean \pm standard deviation for continuous variables and as frequencies for categorical variables. Continuous variables were compared between groups using the Mann-Whitney-test $(n<30)$.

Allele frequency comparisons were predicted using the Chi-square test. If a sample size fell short of five cases, the Fisher's exact test was used. The relative risks of the disease for a particular allele or genotype were estimated by odds ratios (ORs) (Bland and Althman, 2000). The OR was calculated using the following formula: $O R=(a \cdot d) /(b \cdot c)$, where 
allele (genotype) frequency in the patient sample, b-allele (genotype) frequency in the hold-out sample, c-a total of other allele (genotypes) frequencies in the patient sample, $d-a$ total of the other allele (genotypes) frequencies in the hold-out sample. The OR is presented with $95 \%$ confidence interval (CI) (Fleiss, 1989; Lakin, 1990). In the case of impossible estimation of OR, the hazard ratio (HR) was used. All statistical analysis was performed using SPSS version 20.0. Differences were regarded as statistically significant if the null hypothesis was rejected with probability $>95 \%(p<0.05)$.

\section{Results and Discussion}

The results of DNA samples genotyping of volunteers and patients with CAD are shown in the Table 1. While comparing the frequency of genotypes rs5918, rs6065, rs2046934, rs4244285, and rs4986893 in the group of patients with CAD and the control group, there was no significant difference declared. We should emphasize as well that no mutant allele A of the polymorphism rs4986893 of cytochrome P450 geneCYP2C19*3 was found in neither the group of patients nor the control group. That is the reason we excluded it from further comparative analysis.

It is interesting to note that according to the literature, the frequency of CYP2C19 genotypes (carrying allele variants of CYP2C19*2 and CYP2C19*3-for slow metabolizers) in the Russian population amounts to $11.4 \%$, compared to European ethnic groups (Gaikovitch et al., 2003), but CYP2C19 genotypes, connected with slow metabolism, could be up to $27 \%$ in patients with chronic heart disease (CHD) (Komarov

Table 1. Genotypes Frequencies for Six Single Nucleotide Polymorphisms IN The Research Population and Control Group

\begin{tabular}{|c|c|c|c|c|c|c|}
\hline \multirow{2}{*}{$\frac{\text { Gene, SNP }}{\text { ITGB3, } 176 \text { T>C, rs5918 }}$} & \multirow{2}{*}{$\begin{array}{l}\begin{array}{c}\text { Genotype, } \\
\text { allele }\end{array} \\
\text { TT } \\
\text { TC } \\
\text { CC } \\
\text { TT } \\
\text { TC+CC } \\
\text { T-allele } \\
\text { C-allele }\end{array}$} & \multicolumn{2}{|c|}{$\begin{array}{l}\text { Frequencies in the research group } \\
\text { (patients with } C H D), \mathrm{n}=130, \mathrm{n}(\%)\end{array}$} & \multicolumn{2}{|c|}{$\begin{array}{l}\text { Frequencies in the } \\
\text { control group, } \\
\mathrm{n}=185, \mathrm{n}(\%)\end{array}$} & $\frac{\mathrm{p}}{0.81}$ \\
\hline & & $n=91$ & $\begin{aligned} 58 & (63.5) \\
31 & (33.8) \\
2 & (2.7) \\
58 & (63.5) \\
33 & (35) \\
147 & (80.8) \\
35 & (19.2)\end{aligned}$ & $n=174$ & $\begin{aligned} & 115(66.1) \\
& 54(31.0) \\
& 5(2.9) \\
& 115(66.1) \\
& 59(33.9) \\
& 284(83) \\
& 58(17)\end{aligned}$ & $\begin{array}{l}0.57 \\
0.52\end{array}$ \\
\hline GP1BA, Thr145Met, rs6065 & $\begin{array}{l}\mathrm{CC} \\
\mathrm{CT} \\
\mathrm{TT} \\
\mathrm{CC} \\
\text { CT+TT } \\
\text { C-allele } \\
\text { T-allele }\end{array}$ & $n=114$ & $\begin{aligned} 80 & (70.1) \\
30 & (26.3) \\
4 & (3.5) \\
80 & (70.1) \\
34 & (29.9) \\
190 & (83.3) \\
38 & (16.7)\end{aligned}$ & $n=174$ & $\begin{aligned} 133 & (76.4) \\
38 & (21.8) \\
3 & (1.7) \\
133 & (76.4) \\
41 & (23.6) \\
304 & (87.4) \\
44 & (12.6)\end{aligned}$ & $\begin{array}{l}0.24 \\
0.18\end{array}$ \\
\hline ITGA2, 807 C>T, rs1126643 & $\begin{array}{l}\text { CC } \\
\text { CT } \\
\text { TT } \\
\text { CC } \\
\text { CT+TT } \\
\text { C-allele } \\
\text { T-allele }\end{array}$ & $n=94$ & $\begin{aligned} 44 & (46.8) \\
42 & (44.7) \\
8 & (8.5) \\
44 & (46.8) \\
50 & (53.2) \\
130 & (69.1) \\
58 & (30.9)\end{aligned}$ & $n=171$ & $\begin{aligned} & 56(32.7) \\
& 91(53.2) \\
& 24(14.1) \\
& 56(32.7) \\
& 115(67.3) \\
& 203(59.4) \\
& 139(40.6)\end{aligned}$ & $\begin{array}{l}0.02 \\
0.03\end{array}$ \\
\hline P2RY12, 744T>C, rs2046934 & $\begin{array}{l}\mathrm{H} 1 \mathrm{H} 1 \\
\mathrm{H} 1 \mathrm{H} 2 \\
\mathrm{H} 2 \mathrm{H} 2 \\
\mathrm{H} 1 \mathrm{H} 1 \\
\text { H1H2+H2H2 } \\
\text { T-allele } \\
\text { C-allele }\end{array}$ & $n=100$ & $\begin{aligned} & 83(83) \\
& 19(19) \\
& 8(8) \\
& 83(83) \\
& 27(27) \\
& 185(84.1) \\
& 35(15.9)\end{aligned}$ & $n=180$ & $\begin{aligned} 128 & (71.1) \\
43 & (23.9) \\
9 & (5.0) \\
128 & (71.1) \\
52 & (28.9) \\
299 & (83.1) \\
61 & (16.9)\end{aligned}$ & $\begin{array}{l}0.42 \\
0.74\end{array}$ \\
\hline CYP2C19*2, 681G>A, rs4244285 & $\begin{array}{l}* 1 / * 1 \\
* 1 / * 2 \\
* 2 / * 2 \\
* 1 / * 1 \\
* 1 / * 2+* 2 / * 2 \\
* 1 \text { allele } \\
* 2 \text { allele }\end{array}$ & $n=84$ & $\begin{aligned} 69 & (82.1) \\
14 & (16.7) \\
1 & (1.2) \\
69 & (82.1) \\
15 & (17.9) \\
152 & (90.5) \\
16 & (9.5)\end{aligned}$ & $n=30$ & $\begin{aligned} 23 & (76.7) \\
6 & (20.0) \\
1 & (3.3) \\
23 & (76.7) \\
7 & (23.3) \\
52 & (86.7) \\
8 & (13.3)\end{aligned}$ & $\begin{array}{l}0.51 \\
0.41\end{array}$ \\
\hline CYP2C19*3, 636G >A, rs4986893 & $\begin{array}{l}* 1 / * 1 \\
* 1 / * 3 \\
* 3 / * 3\end{array}$ & $n=83$ & $\begin{array}{c}83(100) \\
0 \\
0\end{array}$ & $n=30$ & $\begin{array}{l}30(100) \\
0 \\
0\end{array}$ & 1 \\
\hline
\end{tabular}

H1-haplotype 139C, 744T, no, 52G; H2-haplotype 139T, 744C, ins801A, 52T; CYP2C19*2: variant *1/*1-genotype GG, *1/*2genotype GA, *2/*2—genotype AA; CYP2C19*3: *1*1-genotype GG, *1/*3-genotype GA, *3/*3-genotype AA.

CHD, chronic heart disease; SNP, single nucleotide polymorphism. 
et al., 2011). In our case, CYP2C19 genotypes connected with slow metabolism demonstrated the frequency of $17.9 \%$, which is more often than in total population but less common than in patients with CHD in other regions.

The frequency of mutant allele T of ITGA2 gene rs 1126643 was significantly higher in the control group in comparison with patients with CAD. Genotype CC was revealed in $46.8 \%$ of patients, heterozygous CT genotype in $44.7 \%$, and genotype TT in $8.5 \%$ of them. In the control group, genotype $\mathrm{CC}$ was detected in $32.7 \%$ of volunteers, heterozygous CT genotype in $53.2 \%$, and genotype TT in $14.1 \%(p=0.025)$. Gene ITGA2 encodes the amino acid sequence of integrin alfa2subunits (collagen receptors). Here, the allele $807 \mathrm{C}$ is associated with low density of platelet membrane receptors and the allele 807T is associated with high expression of the gene (Weiss et al., 1996).

According to the literature data, the allele variant frequency of this polymorphism in the European population is the following: $\mathrm{CC}-26.5 \%, \mathrm{CT}-59.8 \%$, and TT $-13.7 \%$ (Lewandowski et al., 2005), which compiles the frequency in the control group in our study.

We did not detect any significant distinctions in platelet aggregation with ADP $(5 \mu \mathrm{M})$ and AA $(1 \mathrm{mM})$ between patients with genotype $\mathrm{CC}$ and patients with genotypes $\mathrm{CT}$ plus TT of polymorphism rs1126643 neither before CABG nor 1-3 and 8-10 days after CABG. Aggregation amplitude with ADP before CABG and 1-3, 8-10 days after CABG in carriers of mutant $\mathrm{T}$ allele of polymorphism rs 1126643 versus carriers of dominant allele in homozygous genotype was the following: $48.8 \% \pm 18.6 \%, 62.0 \% \pm 13.0 \%, 49.8 \% \pm 23.2 \%$ versus $51.5 \% \pm 22.3 \%, 57.4 \% \pm 14.6 \%, 45.8 \% \pm 22.9$, respectively ( $p=0.497,0.441$, and 0.687 ). The estimation of aggregation amplitude with AA before CABG, and on 1st- 3rd, 8th-10th days after CABG in carriers of mutant $\mathrm{T}$ allele of polymorphism rs 1126643 versus carriers of dominant allele in homozygous genotype allowed us to reveal the following levels: $61.3 \% \pm 28.6 \%, 17.5 \% \pm 23.8 \%, 28.0 \pm 30.5$ versus $71.3 \% \pm 21.8 \%, 16.9 \% \pm 22.7 \%, 29.9 \% \pm 33.5 \%$, respectively ( $p=0.416,0.825$, and 0.872 ). The polymorphism rs 1126643 was not associated with high platelet aggregation after CABG.

The literature data about the association of the polymorphism rs 1126643 with atherothrombosis are controversial. In the meta-analysis of $\mathrm{Wu}$ et al. (2014) fifteen studies with 2242 cases and 2408 controls were included. This metaanalysis has demonstrated an association between the C807T polymorphism and the risk of ischemic stroke in the overall Asians and the subgroup of hospital-based people population. However, a statistical association was not found for Caucasians and non-hospitalized individuals.

It is known that the glycoprotein (GP) Ia receptor or integrin $\alpha 2 \beta 1$ (platelet collagen receptor) refers to the integrin family that takes part in the intercellular interaction. The genotype 807TT is associated with high density of platelet membrane receptors and high risk of retinal vessels thrombosis development, stroke, and myocardial infarction (MI) (Dodson et al., 2003; Langsenlehner et al., 2006). However, not all studies contain unambiguous data on this issue (Ye et al., 2006; Gerger et al., 2009; Motovska et al., 2010).

Carriers of mutant allele from patients with CAD of polymorphism rs5918 ITGB3 gene (the mutation that leads to increased expression of fibrinogen receptors on the membrane) may have higher levels of platelet aggregation with AA on 1st-3rd day after CABG $(1 \mathrm{mM})$. Aggregation amplitude with AA in mutant allele carriers was $27.5 \%$ versus

Table 2. The Aggregation Level in Patients with Coronary Artery Disease with Different Genotype Variants of Rs5918 in ITGB3 Gene

\begin{tabular}{|c|c|c|c|}
\hline Index & $\begin{array}{l}\text { Group of patients with } \\
C A D(\text { genotype } T T),(\mathrm{n}=47)\end{array}$ & $\begin{array}{l}\text { Group of patients with } C A D \\
\text { (genotype } T C+C C),(\mathrm{n}=24)\end{array}$ & $\mathrm{p}$ \\
\hline APTT before CABG & $28.7 \pm 3.2$ & $27.9 \pm 3.2$ & 0.308 \\
\hline Fibrinogen before $\mathrm{CABG}, \mathrm{g} / \mathrm{L}$ & $3.1 \pm 0.69$ & $3.1 \pm 0.7$ & 0.746 \\
\hline PT before CABG & $11.9 \pm 2.45$ & $11.2 \pm 2.3$ & 0.897 \\
\hline $\begin{array}{l}\text { Platelet aggregation (amplitude) with } 5 \mu \mathrm{M} \\
\text { ADP before CABG }\end{array}$ & $52.0 \pm 23.5$ & $56.8 \pm 21.0$ & 0.561 \\
\hline $\begin{array}{l}\text { Platelet aggregation (amplitude) with } 1 \mathrm{mM} \\
\text { arachidonic acid before CABG }\end{array}$ & $64.75 \pm 26.5$ & $60.96 \pm 29.9$ & 0.761 \\
\hline $\begin{array}{l}\text { Platelet aggregation (amplitude) with } 5 \mu \mathrm{M} \\
\text { ADP at } 1-3 \text { days after CABG }\end{array}$ & $59.1 \pm 15.8$ & $66.4 \pm 15.0$ & 0.074 \\
\hline $\begin{array}{l}\text { Platelet aggregation (amplitude) with } 1 \mathrm{mM} \\
\text { arachidonic acid at } 1-3 \text { days after CABG }\end{array}$ & $12.7 \pm 16.2$ & $27.5 \pm 31.1$ & 0.016 \\
\hline $\begin{array}{l}\text { Platelet aggregation (velocity) with } 1 \mathrm{mM} \\
\text { arachidonic acid at } 1-3 \text { days after CABG }\end{array}$ & $32.8 \pm 20.8$ & $47.0 \pm 26.4$ & 0.025 \\
\hline $\begin{array}{l}\text { Platelet aggregation (lag-phase) with } 1 \mathrm{mM} \\
\text { arachidonic acid at } 1-3 \text { days after CABG }\end{array}$ & $23.9 \pm 42.6$ & $30.2 \pm 61.3$ & 0.616 \\
\hline $\begin{array}{l}\text { Platelet aggregation (area) with } 1 \mathrm{mM} \\
\text { arachidonic Acid at } 1-3 \text { days after CABG }\end{array}$ & $55.6 \pm 74.9$ & $97.9 \pm 103.6$ & 0.040 \\
\hline $\begin{array}{l}\text { Platelet aggregation (amplitude) with } 5 \mu \mathrm{M} \\
\text { ADP at } 8-10 \text { days after CABG }\end{array}$ & $38.4 \pm 23.9$ & $44.7 \pm 22.0$ & 0.228 \\
\hline $\begin{array}{l}\text { Platelet aggregation (amplitude) with } 1 \mathrm{mM} \\
\text { arachidonic acid at } 8-10 \text { days after CABG }\end{array}$ & $32.9 \pm 31.8$ & $24.3 \pm 26.7$ & 0.160 \\
\hline
\end{tabular}

Mann-Whitney test $(n 1=47, n 2=24)$.

ADP, adenosine diphosphate; APTT, activated partial thromboplastin time; CABG, coronary artery bypass grafting; CAD, coronary artery disease; PT, protrombin time. 
$12.7 \%$ in carriers of homozygous dominant allele, aggregation velocity was $47 \%$ versus $32.8 \%$, and area under the curve $97.9 \%$ versus $55.6 \%$, respectively, $(p<0.05)$. This fact emphasizes the necessity of the ASA administration even on the first day after CABG. On the 8th-10th day of antiplatelet treatment platelet aggregation characteristics did not differ significantly (Table 2 ).

Numerous studies demonstrated the association between allele $\mathrm{C}$ of the ITGB3 gene polymorphism (Leu33Pro, rs5918) with increased platelet reactivity and aggregation and/or fibrinogen binding capacity (Dropinski et al., 2007; Lim et al., 2007). Other investigators did not find the influence of $\mathrm{C}$ allele on the platelet reactivity (Morawski et al., 2005). In the study of Abderrazek et al. (2010), genotypes frequency of platelet GPIII receptors gene were as follows: $\mathrm{TT}-55.3 \%, \mathrm{CT}-39.4 \%$, and $\mathrm{CC}-5.3 \%$.

Kucharska-Newton et al. (2011) in the study Atherosclerosis Risk in Communities (ARIC), with participation of 1202 patients, observed the mutant allele of polymorphism rs5918 was associated with increased level of platelet activation (enhanced level of P-selecting expression) and atheroma cap thinning.

No differences in platelet reactivity among carriers of other mentioned mutant alleles and wild types were observed.

In 34 patients, with full data concerning 6 studied polymorphisms, we have analyzed their association with CVE after CABG. During the follow-up period $12 \mathrm{CVE}$ were registered: 3 strokes, 6 AMI, and 3 deaths.

We compared the group of patients that have met end points $(n=12)$ and the group of patients without CVE during the follow-up period by the presence of mutant alleles of studied polymorphisms. It was indicated that the patients with combinations of mutant alleles of ITGB3+CYP2C19*2 genes, CYP2C19*2+ITGA2 genes, or mutant allele of CYP2C19*2 gene met end points more often compared to other gene combination (wild-type homozygote, presence of one mutant allele of ITGB3 or ITGA2, the composite of mutant alleles of ITGB3+ITGA2 or ITGB3+ITGA2+CYP2C19*2; $p=0.008, \mathrm{HR}=4$, CI 2.19-7.29).

It should be mentioned that in listed variants of combination the one including mutant loss-of-function allele of polymorphism rs4244285 of the cytochrome P450 gene, the enzyme converting clopidogrel to its active metabolite, was the most unfavorable. It is a polymorphism that is likely to

Table 3. Association of Mutant Allele of Single Nucleotide Polymorphisms with Cardiovascular Outcomes After Coronary Artery Bypass Grafting

\begin{tabular}{lccc}
\hline Gene, polymorphism & OR & $95 \%$ CI & $\mathrm{p}$ \\
\hline $\begin{array}{l}\text { ITGB3, } 176 \text { T>C, rs5918, } \\
\quad n=80\end{array}$ & 0.284 & $0.032-2.486$ & 0.225 \\
$\begin{array}{l}\text { GP1BA, Thr145Met, rs6065, } \\
\quad 0.563\end{array}$ & $0.112-2.820$ & 0.484 \\
$\quad \begin{array}{l}\text { ITGA2, 807 C>T, rs1126643, } \\
\quad n=64\end{array}$ & 0.871 & $0.162-4.680$ & 0.872 \\
$\begin{array}{l}\text { CYP2C19*2, 681G }>\text { A, } \\
\quad \text { rs4244285, } n=73\end{array}$ & 1.543 & $0.279-8.532$ & 0.619 \\
$\begin{array}{l}\text { P2RY12, rs2046934, } n=87 \\
\quad\end{array}$ & 0.281 & $0.033-2.376$ & 0.244 \\
\hline
\end{tabular}

CI, confidence interval; OR, odds ratio. resist clopidogrel. Most of 12 patients who met end points ( 8 patients, $66.7 \%$ ) after $\mathrm{CABG}$ received dual antiplatelet therapy (due to the history of AMI and/or stenting less than a year before $\mathrm{CABG}$ ). Therefore, we may suggest that dual antiplatelet therapy is less effective in adverse CVE prevention in carriers of mutant allele combinations of ITGB3+ CYP2C19*2, CYP2C19*2+ITGA2 genes, or mutant allele of CYP2C19*2 gene.

According to the literature data, CYP2C19 allele frequency differs within ethnic groups (Mirzaev et al., 2014). Sibbing et al. (2009) demonstrated that $73 \%$ patients in German population were CYP2C19 wild-type homozygotes (*1/*1), 27\% had heterozygous type of $* 2$ allele $(* 1 / * 2)$, and only $2 \%$ carried mutant-type homozygotes CYP2C19*2 (*2/*2).

The features of clopidogrel pharmacodynamics and pharmacokinetics depend on mutant allele carriage. It is well established in RECLOSE trial (Varenhorst et al., 2009) where 772 patients were enrolled with different clinical variants of CHD (ST elevation and non-ST elevation MI) undergoing drug eluting stenting. Carriers of mutant allele CYP2C19*2 polymorphism had higher levels of ADP-induced platelet reactivity than carriers of wild allele. Various studies have demonstrated the association of mutant CYP2C19 allele with weakened antiplatelet response to clopidogrel and high risk of CVE (Collet et al., 2009; Frere et al., 2009).

A genetic substudy in TRITON-TIMI 38, with 1500 patients on clopidogrel treatment, showed significant increasing risk of cardiovascular death, AMI, and stroke in carriers of at least one mutant allele (27.1\% of patients; OR $1.53,95 \%$ CI 1.07-2.19, $p=0.01$ ) (Mega et al., 2009).

The genetic substudy of 10,285 patients in PLATO trial reported that loss-of-function CYP2C19 $(* 2, * 3-* 8)$ alleles associated with higher risk of CVE in a 30 days period $(5.7 \%$ vs. $3.8 \%, p=0.028)$ in patients with AMI on clopidogrel treatment. However, after 1 year period this distinction was not significant (Wallentin et al., 2010).

In the analysis of Holmes et al. (2011) in 32 studies (42,016 patients), the clinical relationship between genotype and cardiovascular outcomes was not found, except stent thrombosis. Substudies CURE and ACTIVE showed the same results (Pare et al., 2010).

In our study, the mutant allele of cytochrome P450 gene was not associated with CVE (Table 3). The carriage of mutant alleles combination of cytochrome P450 gene, collagen receptors gene, and fibrinogen receptors gene, but not isolated carriage of mutant allele of cytochrome $\mathrm{P} 450$ gene increased the risk of adverse CVE after CABG. This indicates the necessity to investigate polymorphism combination influence on a factor but not the influence of a single polymorphism, especially if the encoded feature is involved in the complex process.

It was logical to expect the probability of higher cardiovascular risk in patients with mutant allele combinations of ITGB3+ITGA2+CYP2C19*2 genes, however, we did not find this negative association because only one patient had this combination.

This research has the limitation as the study group of patients after CABG was small.

\section{Conclusions}

The analysis of mutant allele association in the following polymorphisms: rs2046934 of ADP-platelet receptor gene 
P2RY12; rs1 126643 of collagen receptor gene ITGA2; rs5918 of fibrinogen receptor gene ITGB3; rs6065 of von Willebrand factor receptor gene GP1BA; rs4244285 of cytochrome P450 CYP2C19*2 gene; and rs4986893 cytochrome P450 CYP2C19*3 gene with primary end points has demonstrated that patients who underwent $\mathrm{CABG}$ with mutant allele combinations of ITGB $3+\mathrm{CYP} 2 \mathrm{C} 19 * 2$, CYP2C19*2+ITGA2, or CYP2C19*2 genes met primary end point more often compared to carriers of other alleles combinations (wild-type homozygote, presence of one mutant allele of ITGB3 or ITGA2, or the composite of mutant alleles of ITGB3+ITGA2 or ITGB3+ITGA2+CYP2C19*2). Carriage of the combination of mutant alleles ITGB3+CYP2C19*2 or CYP2C19*2+ ITGA2 or CYP2C19*2 is a possible predictor of CVE in patients after $\mathrm{CABG}$.

\section{Author Disclosure Statement}

No competing financial interests exist.

\section{References}

Abderrazek F, Chakroun T, Addad F, et al. (2010) The GPIIIa PlA polymorphism and the platelet hyperactivity in Tunisian patients with stable coronary artery disease treated with aspirin. Thromb Res 125:E265-E268.

Bland JM, Altman DG (2000) Statistics notes. Br Med J 320: 1468.

Cavallari U, Trabetti E, Malerba G, et al. (2007) Gene sequence variations of the platelet $\mathrm{P} 2 \mathrm{Y} 12$ receptor are associated with coronary artery disease. BMC Med Genet 8:59.

Collet JP, Hulot JS, Pena ANA, et al. (2009) Cytochrome P450 2C19 polymorphism in young patients treated with clopidogrel after myocardial infarction: impact on clinical events and on. Eur Heart J 30:906.

Dodson PM, Haynes J, Starczynski J, et al. (2003) The platelet glycoprotein Ia/Iia gene polymorphism C807T/G873A: a novel risk factor for retinal vein occlusion. Eye 17:772-777.

Dropinski J, Musial J, Sanak M, et al. (2007) Antithrombotic effects of aspirin based on PLA1/A2 glycoprotein Illa polymorphism in patients with coronary artery disease. Thromb Res 119:301-303.

Fleiss JL (1989) Statistical Methods for Rates and Proportions, $2^{\text {nd }}$ ed. John Wiley and Sons, New York, NY.

Frere C, Cuisset T, Gaborit B, et al. (2009) The CYP2C19*17 allele is associated with better platelet response to clopidogrel in patients admitted for non-ST acute coronary syndrome. J Thromb Haemost 7:1409-1411.

Gaikovitch EA, Cascorbi I, Mrozikiewicz PM, et al. (2003) Polymorphisms of drug-metabolizing enzymes CYP2C9, CYP2C19, CYP2D6, CYP1A1, NAT2 and of P-glycoprotein in a Russian population. Eur J Clin Pharmacol 59:303-312.

Geisler T, Schaeffeler E, Gawaz M, et al. (2013) Genetic variation of platelet function and pharmacology: an update of current knowledge. Thromb Haemost 110:876-887.

Gerger A, Hofmann G, Langsenlehner U, et al. (2009) Integrin alpha- 2 and beta- 3 gene polymorphisms and colorectal cancer risk. Int J Colorectal Dis 24:159-163.

Grinshtein YI, Kosinova AA, Grinstein IY, et al. (2016) Clinical and laboratory features of resistant to acetylsalicylic acid patients with coronary heart disease in the perioperative period of coronary artery bypass grafting: results of an open prospective study. Rational Pharmacother Cardiol 12:264 270.
Grinshtein YI, Savchenko AA, Filonenko IV, et al. (2009) Zilt versus aspirin in patients with coronary atherosclerosis after coronary artery bypass surgery. Key findings ZEUS: efficacy, mechanism of resistance to acetylsalicylic acid, the immediate and long-term clinical results. Cardiovasc Ther Prev 8: $36-43$.

Holmes MV, Perel P, Shah T, et al. (2011) CYP2C19 genotype, clopidogrel metabolism, platelet function, and cardiovascular events. A systematic review and meta-analysis. JAMA 306: 2704-2714.

Hoppmann P, Koch W, Laugwitz KL, et al. (2014) Genetic risk of restenosis after percutaneous coronary interventions in the era of drug-eluting stents. Coron Artery Dis 25:658664.

Jones CI, Bray S, Garner SF, et al. (2009) A functional genomics approach reveals novel quantitative trait loci associated with platelet signaling pathways. Blood 114: 1405-1416.

Komarov AL, Panchenko EP, Donnikov AE, et al. (2011) Factors that determine the clopidogrel clinical efficacy and prognosis in patients with stable coronary heart disease. Cardiologiya 51:8-18.

Kucharska-Newton AM, Monda KL, Campbell S, et al. (2011) Association of the platelet GPIIb/IIIa polymorphism with atherosclerotic plaque morphology: the Atherosclerosis Risk in Communities (ARIC) Study. Atherosclerosis 216:151-156.

Lakin GF (1990) Biometrics [in Russian]. Vysshaya shkola, Moscow.

Langsenlehner U, Renner W, Yazdani-Biuki B, et al. (2006) Integrin alpha- 2 and beta-3 gene polymorphisms and breast cancer risk. Breast Cancer Res Treat 97:67-72.

Lewandowski K, Swierczynska A, Kwasnikowski $\mathrm{P}$, et al. (2005) The prevalence of C807T mutation of glycoprotein Ia gene among young male survivors of myocardial infarction: a relation with coronary angiography results. Kardiol Pol 63: 107; discussion 114.

Lim E, Carballo S, Cornelissen J, et al. (2007) Dose-related efficacy of aspirin after coronary surgery in patients with Pl(A2) polymorphism (NCT00262275). Ann Thorac Surg 83: 134-139.

Lytech.ru (2011) Instructions for working with sets of NPF "Liteh" (SNPexpressfarmgen set and SNPexpresscardiogen set) [in Russian]. Available at www.lytech.ru/instr.htm (accessed December 20, 2011).

Maguire JM, Thakkinstian A, Sturm J, et al. (2008) Polymorphisms in platelet glycoprotein $1 \mathrm{~b}$ alpha and factor VII and risk of ischemic stroke. Stroke 39:1710-1716.

Mega JL, Close SL, Wiviott SD, et al. (2009) Cytochrome P450 polymorphisms and response to clopidogrel. N Engl J Med 360:354-362.

Mirzaev KB, Sychev DA, Andreev DA. (2004) Ethnic differences of the CYP2C19 gene polymorphism associated with the volation of the response to clopidogrel in the Russian Federation. Mol Med 1:13-21.

Moon JY, Franchi F, Rollini F, et al. (2018) Role of genetic testing in patients undergoing percutaneous coronary intervention. Expert Rev Clin Pharmacol 11:151-164.

Morawski W, Sanak M, Cisowski M, et al. (2005) Prediction of the excessive perioperative bleeding in patients undergoing coronary artery bypass grafting: role of aspirin and platelet glycoprotein IIIa polymorphism. J Thorac Cardiovasc Surg 130:791-796.

Motovska Z, Kvasnicka J, Widimsky P, et al. (2010) Platelet glycoprotein GP VI $13254 \mathrm{C}$ allele is an independent risk 
factor of premature myocardial infarction. Thromb Res 125: E61-E64.

Muslimova EF, Afanasiev SA, Rebrova TY, et al. (2017) Association of ITGB3, P2RY12, and CYP2C19 gene polymorphisms with platelet functional activity in patients with coronary heart disease during dual antiplatelet therapy. Ter Arkh 89:74-78.

Pare G, Mehta SR, Yusuf S, et al. (2010) Effects of CYP2C19 genotype on outcomes of clopidogrel treatment. N Engl J Med 363:1704-1714.

Quinn MJ, Topol EJ (2001) Common variations in platelet glycoproteins: pharmacogenomic implications. Pharmacogenomics 2:341-352.

Sarikaya S, Aydin E, Ozen Y, et al. (2017) The role of genetics in coronary artery bypass surgery patients under 30 years of age. Cardiovasc J Afr 28:77-80.

Sibbing D, Stegherr J, Latz W, et al. (2009) Cytochrome P450 2C19 loss-of-function polymorphism and stent thrombosis following percutaneous coronary intervention. Eur Heart J 30: 916-922.

Varenhorst C, James S, Erlinge D, et al. (2009) Genetic variation of CYP2C19 affects both pharmacokinetic and pharmacodynamic responses to clopidogrel but not prasugrel in aspirin-treated patients with coronary artery disease. Eur Heart J 30:1744-1752.

Wallentin L, James S, Storey RF, et al. (2010) Effect of CYP2C19 and ABCB1 single nucleotide polymorphisms on outcomes of treatment with ticagrelor versus clopidogrel for acute coronary syndromes: a genetic substudy of the PLATO trial. Lancet 376:1320-1328.

Weiss EJ, Bray PF, Tayback M, et al. (1996) A polymorphism of a platelet glycoprotein receptor as an inherited risk factor for coronary thrombosis. N Engl J Med 334:1090-1094.

Wu G, Xi Y, Yao L, et al. (2014) Genetic polymorphism of ITGA2 C807T can increase the risk of ischemic stroke. Int $\mathbf{J}$ Neurosci 124:841-851.

Ye Z, Liu EHC, Higgins JPT, et al. (2006) Seven haemostatic gene polymorphisms in coronary disease: meta-analysis of 66 155 cases and 91307 controls. Lancet 367:651-658.

Zuern CS, Schwab M, Gawaz M, et al. (2010) Platelet pharmacogenomics. J Thromb Haemost 8:1147-1158.

Address correspondence to: Alexandra A. Kosinova Therapeutic Department of Institute of Postgraduate Education

Krasnoyarsk State Medical University named after Professor V.F. Voyno-Yaseneckiy 1, Partizan Zheleznyak Street Krasnoyarsk 660022 Russian Federation

E-mail: alexandrakosinova@gmail.com 